\title{
Risk of cardiovascular disease and mortality in overweight and obese patients with type 2 diabetes: an observational study in 13,087 patients
}

\author{
K. Eeg-Olofsson • J. Cederholm • P. M. Nilsson • \\ B. Zethelius • L. Nunez • S. Gudbjörnsdóttir • \\ B. Eliasson
}

Received: 1 August 2008 / Accepted: 3 October 2008 / Published online: 5 November 2008

(C) Springer-Verlag 2008

\begin{abstract}
Aims/hypothesis The aim of this study of type 2 diabetic patients in the Swedish National Diabetes Register was to study the associations of BMI, overweight (BMI 25$\left.29.9 \mathrm{~kg} / \mathrm{m}^{2}\right)$ and obesity (BMI $\geq 30 \mathrm{~kg} / \mathrm{m}^{2}$ ) with cardiovascular disease in type 2 diabetes, as these associations have not previously been clarified.

Methods Patients aged 30-74 years with no previous CHD or stroke $(N=13,087)$ were followed for a mean of 5.6 years until 2003 for fatal or non-fatal CHD, stroke, cardiovascular disease (CHD or stroke) and total mortality. In total, 1,922 cardiovascular-disease events occurred, based on 64,864 person-years.
\end{abstract}

K. Eeg-Olofsson $(\bowtie) \cdot$ L. Nunez $\cdot$ S. Gudbjörnsdóttir

B. Eliasson

Department of Medicine, Sahlgrenska University Hospital,

University of Gothenburg,

41345 Göteborg, Sweden

e-mail: katarina.eeg-olofsson@vgregion.se

J. Cederholm

Family Medicine and Clinical Epidemiology Section,

Department of Public Health and Caring Sciences,

Uppsala University,

Uppsala, Sweden

P. M. Nilsson

Department of Clinical Sciences, Lund University,

University Hospital,

Malmö, Sweden

B. Zethelius

Geriatrics Section,

Department of Public Health and Caring Sciences,

Uppsala University,

Uppsala, Sweden
Results The relative risks of CHD, stroke, cardiovascular disease and total mortality for a 5 unit increase in BMI at baseline were $15 \%, 11 \%, 13 \%$ and $27 \%$, respectively, using Cox regression analysis, after adjusting for age, sex, diabetes duration, hypoglycaemic treatment and smoking (model 1), and were $9 \%, 4 \%$ (not significant), $7 \%$ and $20 \%$, respectively, when adjusting also for $\mathrm{HbA}_{1 \mathrm{c}}$, blood pressure, antihypertensive drugs, lipid-reducing drugs and microalbuminuria (model 2). Adjusted hazard ratios (model 1) for CHD, cardiovascular disease and total mortality with overweight were 1.27 (95\% CI 1.09-1.48), 1.24 (1.09-1.41) and 1.16 (0.94-1.45), respectively, and 1.49 (1.27-1.76), 1.44 (1.26$1.64)$ and 1.71 (1.36-2.14) with obesity, as compared with normal weight. Significant hazard ratios were attenuated when adjusted according to model 2. For a 1 unit increase in BMI during follow-up, the relative risk of CHD (model 2) was $1.13(1.04-1.23 ; p=0.005)$.

Conclusions/interpretation Both overweight and obesity independently increased the risk of CHD and cardiovascular disease in patients with type 2 diabetes. The CHD risk was higher with increasing BMI than with stable or decreasing BMI during the study.

Keywords BMI · Cardiovascular diseases · Diabetes · Epidemiology $\cdot$ Mortality $\cdot$ Obesity

$\begin{array}{ll}\text { Abbreviations } \\ \text { CVD } & \text { cardiovascular disease } \\ \text { GPRD } & \text { General Practice Research Database } \\ \text { ICD } & \text { International Classification of Diseases } \\ \text { NDR } & \text { National Diabetes Register } \\ \text { OHA } & \text { oral hypoglycaemic agent } \\ \text { UKPDS } & \text { UK Prospective Diabetes Study }\end{array}$




\section{Introduction}

The prevalence of type 2 diabetes is increasing worldwide as a result of the increasing size of the ageing population, improved survival rates and the increasing prevalence of overweight and obesity [1-3]. It is well established that patients with diabetes are at high risk of cardiovascular disease (CVD) and that risk-factor control is of great importance in reducing this risk [4-7]. The association between overweight/obesity and the increased risk of cardiovascular disease is well established in the general population, in both men and women [8-12].

The results are more conflicting in patients with diabetes. Studies have reported inverse, no or positive associations between increasing BMI and CVD and mortality [13-16]. Overweight and obesity are highly prevalent among diabetic patients [17-18]. Previous reports from the National Diabetes Register (NDR) in Sweden have shown improvement in riskfactor control, apart from increasing BMI, in patients with type 2 diabetes over time, and also that obese and overweight patients with type 2 diabetes have higher frequencies of hypertension, dyslipidaemia and microalbuminuria, which are well-known cardiovascular risk factors $[17,19]$.

The aim of the present study, based on data from the Swedish National Diabetes Register, was to describe the associations between BMI, overweight and obesity, fatal or non-fatal CHD, stroke, CVD and total mortality, in female and male type 2 diabetic patients aged 30-74 years. A secondary aim was to analyse associations between weight changes and cardiovascular complications and total mortality. Database-linkage analyses were performed using the Swedish Cause of Death and Hospital Discharge Registers.

\section{Methods}

The Swedish NDR was initiated in 1996 in response to the demands of the St Vincent declaration for quality assurance in diabetes care, and has been described previously [20]. In short, the aims of the NDR are to monitor diabetes care and to encourage the registration of all diabetic patients at least once a year, enabling participating centres to use national results as benchmarking tools for quality assurance in diabetes care. Reporting to the NDR is not mandatory, but all hospital diabetes outpatient clinics and primary healthcare centres are encouraged to participate. All patients gave informed consent before agreeing to be included. The registration of patients is generally carried out by trained nurses or physicians using a printed form, or by transferral of data from clinical record databases. All information is subsequently stored in a central database. Since 2002, it has also been possible to register patients via the Internet (http://www.ndr.nu).
The study, approved by the Regional Ethics Committee at the University of Gothenburg, involved 13,087 female and male type 2 diabetic patients in the NDR, aged 30 74 years, $B M I \geq 18 \mathrm{~kg} / \mathrm{m}^{2}$ and with no previous CHD or stroke, who were followed for 6 years from 1998 to 2003. The epidemiological definition of type 2 diabetes used in this study was: a patient treated with diet or oral hypoglycaemic agent (OHA) only, or a patient treated with insulin alone or in combination with OHA and age $\geq 40$ years at onset of diabetes. Only $1 \%$ were aged below 30 years at onset, and 3\% had age at onset below 40 years. Sixty-seven per cent of all patients were treated in primary healthcare centres and 33\% in hospital outpatient clinics. We also included a subgroup of 4,916 overweight or obese (BMI $25-40 \mathrm{~kg} / \mathrm{m}^{2}$ ) type 2 diabetic patients with data available at baseline and in 2003 .

Baseline Clinical characteristics analysed at baseline were age, sex, duration of diabetes, type of hypoglycaemic treatment, weight, height, smoking, $\mathrm{HbA}_{1 \mathrm{c}}$, blood pressure, use of antihypertensive and lipid-reducing drugs, and microalbuminuria. Baseline values were registered in 1997 and 1998 and were estimated as the mean of 1997 and 1998 values when available. The patients were screened using local methods and devices, but guidelines were available to ensure the use of similar methodology. Body mass index was calculated as weight (in $\mathrm{kg}$ ) divided by height (in $\mathrm{m}$ ) squared. Blood pressure was registered as the mean of two readings (Korotkoff phases 1-5) with the patient sitting or lying down, using a cuff of appropriate size. A smoker was defined as a patient smoking one or more cigarettes per day, or a pipe daily, or someone who had stopped smoking within the past 3 months.

Laboratory analyses were carried out at local laboratories. $\mathrm{HbA}_{1 \mathrm{c}}$ analyses are quality assured in Sweden. Diabetes clinics and primary-care centres both use methods regularly calibrated with the HPLC Mono-S method. In this study, all $\mathrm{HbA}_{1 \mathrm{c}}$ values were converted to the DCCT standard levels using the formula: $\mathrm{HbA}_{1 \mathrm{c}}(\mathrm{DCCT})=(0.923 \times$ $\mathrm{HbA}_{1 \mathrm{c}}\left[\right.$ Mono-S]) $+1.345 ; R^{2}=0.998$ [21]. Microalbuminuria was defined as cumulative urine albumin excretion above $20 \mu \mathrm{g} / \mathrm{min}$ in two out of three consecutive tests.

Follow-up, definition of endpoints All patients were followed from the baseline examination for 6 years, or until the first-incident cardiovascular event or death. Censor date was 31 December 2003. Mean follow-up was 5.6 years. All patients were free from CHD or stroke at baseline. Four major endpoints were used in this study: first-incident fatal or nonfatal CHD, stroke or CVD event, and total mortality. A CVD event was defined as CHD or stroke, whichever came first. A fatal CHD event was defined as fatal ischaemic heart disease (ICD-10 codes I20-I25) or sudden cardiac death (ICD-10 
codes R96.0-1) (http://www.who.int/classifications/icd/en/). A non-fatal CHD event was defined as non-fatal myocardial infarction (ICD-10 code I21), unstable angina (ICD-10 code I20.0), percutaneous coronary intervention and/or coronary artery bypass graft. A stroke event was defined as fatal or non-fatal stroke (ICD-10 codes I61, I63, I64, I67.9). Peripheral vascular disease was not analysed. All endpoint events were retrieved by data linkage with the Swedish Cause of Death and Hospital Discharge Registers, a validated alternative to revised hospital discharge and death certificates [22, 23].

In total, 1,922 first-incident fatal/non-fatal CVD events occurred, based on 64,864 person-years, among all 13,087 participants. In the subgroup of 4,916 patients, change in BMI during the study period was defined as final BMI minus baseline BMI, where final BMI in the case of a fatal event was measured the year before the event and otherwise in 2003. The number of CVD events was 708, based on 24,144 person-years.

Statistical methods Results for continuous variables are described as mean values \pm one $\mathrm{SD}$, and proportions with significance levels for trend of differences were estimated with ANOVA and $\chi^{2}$ test. Cox regression analysis was used for estimation of hazard ratios with $95 \% \mathrm{CI}$ for $\mathrm{CHD}$, stroke, CVD and total mortality. The proportional hazards assumption, requiring constant hazard ratios over time, was tested for all covariates in the models with the Kolmogorov-type supremum test, using resampling, and with the test of all time-dependent covariates simultaneously, and confirmed that this assumption was not rejected for any of the covariates included. The stepwise selection method was also performed to check the results of the analyses with all covariates included. The Hosmer-Lemeshow test demonstrated a non-significant $\chi^{2}$ test for the models used, indicating excellent goodness-of-fit of the models.

Hazard ratios for BMI and $\mathrm{CHD}$, stroke, CVD and total mortality were adjusted for age, sex, diabetes duration, type of hypoglycaemic treatment, smoking and significant interaction variables at baseline (model 1), and also for $\mathrm{HbA}_{1 \mathrm{c}}$, systolic blood pressure, antihypertensive drugs, lipid-lowering drugs, microalbuminuria and significant interaction variables at baseline (model 2). Hazard ratios for change in BMI (final BMI minus baseline BMI) and CHD, stroke, CVD and total mortality were derived, with adjustment according to model 2. Interaction between BMI and all covariates was analysed with maximum-likelihood estimation. Significant interaction variables were added in all Cox regression analyses: smoker $\times$ sex; smoker $\times$ duration, antihypertensives $\times$ systolic BP; antihypertensives $\times$ microalbuminuria; and for analysis of the effect of change in BMI: smoker $\times$ duration, BMI change $\times$ duration, BMI change $\times$ oral hypoglycaemic agents, BMI change $\times$ insulin.
All statistical analyses were performed using SAS version 9.1 (SAS Institute, Cary, NC, USA). A $p$ value below 0.05 was considered statistically significant.

\section{Results}

The baseline characteristics of all 13,087 patients with type 2 diabetes, stratified by BMI level, are shown in Table 1. At baseline, 42\% were overweight (BMI 25-29.9 kg/m²), 38\% were obese $\left(B M I \geq 30 \mathrm{~kg} / \mathrm{m}^{2}\right)$ and $20 \%$ had normal weight $\left(\mathrm{BMI}<25 \mathrm{~kg} / \mathrm{m}^{2}\right)$. Overweight and obese patients had a shorter duration of diabetes, higher $\mathrm{HbA}_{1 \mathrm{c}}$, higher systolic blood pressure, more cases of microalbuminuria and fewer of them were smokers. Of the obese patients, 56\% were using antihypertensive drugs and 14\% were using lipidlowering treatment, as compared with $45 \%$ and $13 \%$ of overweight patients, and $33 \%$ and $9 \%$ of normal-weight patients, respectively.

Adjusted risk estimates Cox regression analyses were performed for all 13,087 patients, followed-up for a mean of 5.6 years, to determine hazard ratios $(95 \% \mathrm{CI})$ for BMI at baseline as continuous variable and first-incident fatal or non-fatal CHD, stroke, CVD and total mortality (Table 2). For a 5 unit increase in BMI, the adjusted hazard ratios were 1.15 (1.08-1.21), 1.11 (1.03-1.19), 1.13 (1.08-1.18) and 1.27 (1.17-1.37), respectively, which were statistically significant after adjustment for age, sex, diabetes duration, type of hypoglycaemic treatment, smoking and significant interactions (model 1). The risks were attenuated, but remained significant except for stroke, after further adjusting for $\mathrm{HbA}_{1 \mathrm{c}}$, microalbuminuria, systolic blood pressure, and use of lipid-lowering and antihypertensive treatment (model 2): 1.09 (1.03-1.16), 1.04 (0.96-1.12), 1.07 (1.02$1.12)$ and $1.20(1.10-1.30)$, respectively. For obesity compared with normal weight, the adjusted hazard ratios (model 1) were: for fatal/non-fatal CHD, 1.49 (1.27-1.76); for fatal/non-fatal stroke, 1.33 (1.08-1.65); for fatal/nonfatal CVD, 1.44 (1.26-1.64); and for total mortality, 1.71 (1.36-2.14). These hazard ratios were somewhat lower, but still strongly significant except for stroke, after adjustment according to model 2 .

Comparing overweight with normal weight, the adjusted hazard ratios were: for fatal/non-fatal CHD, 1.27 (1.09$1.48)$ according to model 1 and $1.18(1.01-1.38)$ according to model 2; and for fatal/non-fatal CVD, 1.24 (1.09-1.41) according to model 1 and $1.14(1.00-1.31)$ according to model 2. The relative risks for stroke and total mortality were not significantly increased in the overweight group.

Case fatality Table 3 shows hazard ratios for fatal and nonfatal events separately. With increasing BMI (per 5 units) at 
Table 1 Clinical characteristics at baseline of 13,087 type 2 diabetic patients (all patients, and stratified by BMI intervals)

\begin{tabular}{|c|c|c|c|c|c|}
\hline Characteristic & All patients & $\mathrm{BMI}<25 \mathrm{~kg} / \mathrm{m}^{2}$ & BMI $25-29.9 \mathrm{~kg} / \mathrm{m}^{2}$ & $\mathrm{BMI} \geq 30 \mathrm{~kg} / \mathrm{m}^{2}$ & $\begin{array}{l}p \text { value } \\
\text { for trend }\end{array}$ \\
\hline Number & 13,087 & 2,676 & 5,491 & 4,920 & \\
\hline BMI $\left(\mathrm{kg} / \mathrm{m}^{2}\right)$ & $29.1 \pm 5.0(18.0-56.1)$ & $23.0 \pm 1.6(18.0-24.9)$ & $27.5 \pm 1.4(25.0-29.9)$ & $34.1 \pm 3.7(30.0-56.1)$ & $<0.001$ \\
\hline Age (years) & $60.3 \pm 9.1(30-74)$ & $60.4 \pm 9.5(30-74)$ & $60.0 \pm 8.9(30-74)$ & $59.7 \pm 9.1(30-74)$ & $<0.001$ \\
\hline Diabetes duration (years) & $8.6 \pm 6.9(1-59)$ & $9.8 \pm 7.8(1-54)$ & $8.9 \pm 7.0(1-58)$ & $7.7 \pm 6.0(1-59)$ & $<0.001$ \\
\hline $\mathrm{HbA}_{1 \mathrm{c}}(\%)$ & $7.64 \pm 1.31(4.3-13.7)$ & $7.56 \pm 1.32(4.7-13.3)$ & $7.58 \pm 1.27(4.3-13.3)$ & $7.74 \pm 1.35(4.6-13.7)$ & $<0.001$ \\
\hline $\begin{array}{l}\text { Systolic blood pressure } \\
(\mathrm{mmHg})\end{array}$ & $145.9 \pm 18.4(88-240)$ & $141.4 \pm 19.1(90-220)$ & $146.2 \pm 18.0(88-220)$ & $148.0 \pm 17.9(90-240)$ & $<0.001$ \\
\hline Men $(\%)$ & 55.7 & 53.8 & 62.7 & 49.0 & $<0.001$ \\
\hline Smokers $(\%)$ & 16.4 & 20.7 & 15.9 & 14.7 & $<0.001$ \\
\hline Antihypertensives (\%) & 47.0 & 33.4 & 45.4 & 56.1 & $<0.001$ \\
\hline Lipid-lowering drugs (\%) & 12.6 & 8.6 & 13.4 & 14.0 & $<0.001$ \\
\hline Microalbuminuria (\%) & 20.9 & 14.5 & 20.3 & 24.9 & $<0.001$ \\
\hline Diet treatment $(\%)$ & 21.7 & 20.5 & 22.0 & 22.1 & NS \\
\hline OHA $(\%)$ & 36.6 & 26.4 & 36.8 & 42.0 & $<0.001$ \\
\hline OHA and insulin (\%) & 12.1 & 8.2 & 11.3 & 15.2 & $<0.001$ \\
\hline Insulin $(\%)$ & 29.5 & 44.9 & 30.0 & 20.7 & $<0.001$ \\
\hline
\end{tabular}

Data shown as mean \pm SD with range (minimum-maximum values) for continuous variables, and frequency (\%) for categorical variables Microalbuminuria: urine albumin $>20 \mu \mathrm{g} / \mathrm{min}$

Significance levels for trend of differences estimated with ANOVA and $\chi^{2}$ test

Table 2 Adjusted hazard ratios for BMI, overweight and obesity at baseline and first-incident fatal/non-fatal CHD, stroke, CVD and total mortality using Cox regression analysis in 13,087 type 2 diabetic patients followed up for 6 years

\begin{tabular}{|c|c|c|c|c|c|c|c|}
\hline \multirow[t]{2}{*}{ Outcome } & \multirow[t]{2}{*}{$\mathrm{BMI}$ as predictor ${ }^{\mathrm{a}}$} & \multirow[t]{2}{*}{ Patients $(n)$} & \multirow[t]{2}{*}{ Events $(n)$} & \multicolumn{2}{|l|}{ Model $1^{\mathrm{b}}$} & \multicolumn{2}{|l|}{ Model $2^{\mathrm{c}}$} \\
\hline & & & & $\operatorname{HR}(95 \% \mathrm{CI})$ & $p$ value & $\operatorname{HR}(95 \% \mathrm{CI})$ & $p$ value \\
\hline Fatal/non-fatal CHD & Per 5 units & 13,087 & 1,326 & $1.15(1.08-1.21)$ & $<0.001$ & $1.09(1.03-1.16)$ & 0.0026 \\
\hline Fatal/non-fatal stroke & Per 5 units & 13,087 & 756 & $1.11(1.03-1.19)$ & 0.0090 & $1.04(0.96-1.12)$ & NS \\
\hline Fatal/non-fatal CVD & Per 5 units & 13,097 & 1,922 & $1.13(1.08-1.18)$ & $<0.001$ & $1.07(1.02-1.12)$ & 0.0073 \\
\hline Total mortality & Per 5 units & 13,087 & 664 & $1.27(1.17-1.37)$ & $<0.001$ & $1.20(1.10-1.30)$ & $<0.001$ \\
\hline \multirow[t]{2}{*}{ Fatal/non-fatal CHD } & $25-29.9$ & 5,491 & 585 & $1.27(1.09-1.48)$ & 0.0028 & $1.18(1.01-1.38)$ & 0.041 \\
\hline & $<25$ & 2,676 & 224 & 1.0 & & 1.0 & \\
\hline \multirow[t]{2}{*}{ Fatal/non-fatal stroke } & $25-29.9$ & 5,491 & 329 & $1.21(0.99-1.48)$ & NS & $1.11(0.91-1.36)$ & NS \\
\hline & $<25$ & 2,676 & 137 & 1.0 & & 1.0 & \\
\hline \multirow[t]{2}{*}{ Fatal/non-fatal CVD } & $25-29.9$ & 5,491 & 839 & $1.24(1.09-1.41)$ & $<0.001$ & $1.14(1.00-1.30)$ & 0.045 \\
\hline & $<25$ & 2,676 & 334 & 1.0 & & 1.0 & \\
\hline \multirow[t]{2}{*}{ Total mortality } & $25-29.9$ & 5,491 & 269 & $1.16(0.94-1.45)$ & NS & $1.08(0.86-1.34)$ & NS \\
\hline & $<25$ & 2,676 & 118 & 1.0 & & 1.0 & \\
\hline \multirow[t]{2}{*}{ Fatal/non-fatal CHD } & $\geq 30$ & 4,920 & 517 & $1.49(1.27-1.76)$ & $<0.001$ & $1.31(1.11-1.55)$ & 0.0018 \\
\hline & $<25$ & 2,676 & 224 & 1.0 & & 1.0 & \\
\hline \multirow[t]{2}{*}{ Fatal/non-fatal stroke } & $\geq 30$ & 4,920 & 290 & $1.33(1.08-1.65)$ & 0.0080 & $1.14(0.91-1.41)$ & $\mathrm{NS}$ \\
\hline & $<25$ & 2,676 & 137 & 1.0 & & 1.0 & \\
\hline \multirow[t]{2}{*}{ Fatal/non-fatal CVD } & $\geq 30$ & 4,920 & 749 & $1.44(1.26-1.64)$ & $<0.001$ & 1.25 (1.09-1.44) & 0.0015 \\
\hline & $<25$ & 2,676 & 334 & 1.0 & & 1.0 & \\
\hline \multirow[t]{2}{*}{ Total mortality } & $\geq 30$ & 4,920 & 277 & $1.71(1.36-2.14)$ & $<0.001$ & $1.47(1.16-1.85)$ & 0.0012 \\
\hline & $<25$ & 2,676 & 118 & 1.0 & & 1.0 & \\
\hline
\end{tabular}

${ }^{\text {a }}$ Per $5 \mathrm{~kg} / \mathrm{m}^{2}$ increase in BMI as a continuous variable, or comparison of two BMI intervals

${ }^{\mathrm{b}}$ Model 1: adjusted for age, sex, type of hypoglycaemic treatment, diabetes duration, smoking and significant interactions

${ }^{\mathrm{c}}$ Model 2: adjusted as in model 1 , and also for $\mathrm{HbA}_{1 \mathrm{c}}$, systolic blood pressure, antihypertensive drugs, lipid-lowering drugs, microalbuminuria $>20 \mu \mathrm{g} / \mathrm{min}$ 
Table 3 Adjusted hazard ratios for BMI and obesity at baseline and fatal or non-fatal first-incident CHD, stroke or CVD using Cox regression analysis in 13,087 type 2 diabetic patients followed-up for 6 years

\begin{tabular}{|c|c|c|c|c|c|c|c|}
\hline \multirow[t]{2}{*}{ Outcome } & \multirow[t]{2}{*}{$\mathrm{BMI}$ as predictor ${ }^{\mathrm{a}}$} & \multirow[t]{2}{*}{ Patients $(n)$} & \multirow[t]{2}{*}{ Events $(n)$} & \multicolumn{2}{|l|}{ Model $1^{\mathrm{b}}$} & \multicolumn{2}{|l|}{ Model $2^{\mathrm{c}}$} \\
\hline & & & & HR $(95 \%$ CI $)$ & $p$ value & $\mathrm{HR}(95 \% \mathrm{CI})$ & $p$ value \\
\hline Fatal CHD & Per 5 units & 13,087 & 418 & $1.29(1.17-1.42)$ & $<0.001$ & $1.21(1.09-1.34)$ & $<0.001$ \\
\hline Non-fatal CHD & Per 5 units & 13,087 & 969 & $1.10(1.03-1.17)$ & 0.0060 & $1.05(0.98-1.13)$ & NS \\
\hline Fatal stroke & Per 5 units & 13,087 & 115 & $1.06(0.87-1.30)$ & NS & $1.00(0.81-1.22)$ & $\mathrm{NS}$ \\
\hline Non-fatal stroke & Per 5 units & 13,087 & 663 & $1.10(1.02-1.19)$ & 0.019 & $1.03(0.95-1.13)$ & NS \\
\hline Fatal CVD & Per 5 units & 13,087 & 505 & $1.24(1.14-1.36)$ & $<0.001$ & $1.16(1.06-1.28)$ & 0.0016 \\
\hline Non-fatal CVD & Per 5 units & 13,087 & 1,519 & $1.08(1.03-1.14)$ & 0.0035 & $1.03(0.98-1.09)$ & NS \\
\hline \multirow[t]{2}{*}{ Fatal CHD } & $\geq 30$ & 4,920 & 173 & $1.79(1.34-2.38)$ & $<0.001$ & $1.49(1.11-2.01)$ & 0.0081 \\
\hline & $<25$ & 2,676 & 70 & 1.0 & & 1.0 & \\
\hline \multirow[t]{2}{*}{ Non-fatal CHD } & $\geq 30$ & 4,920 & 369 & $1.38(1.14-1.68)$ & $<0.001$ & $1.25(1.02-1.52)$ & 0.031 \\
\hline & $<25$ & 2,676 & 163 & 1.0 & & 1.0 & \\
\hline \multirow[t]{2}{*}{ Fatal stroke } & $\geq 30$ & 4,920 & 39 & $1.14(0.67-1.93)$ & NS & $1.04(0.61-1.80)$ & NS \\
\hline & $<25$ & 2,676 & 24 & 1.0 & & 1.0 & \\
\hline \multirow[t]{2}{*}{ Non-fatal stroke } & $\geq 30$ & 4,920 & 256 & $1.32(1.05-1.65)$ & 0.017 & $1.11(0.88-1.40)$ & NS \\
\hline & $<25$ & 2,676 & 121 & 1.0 & & 1.0 & \\
\hline \multirow[t]{2}{*}{ Fatal CVD } & $\geq 30$ & 4,920 & 202 & $1.62(1.25-2.10)$ & $<0.001$ & $1.37(1.05-1.79)$ & 0.019 \\
\hline & $<25$ & 2,676 & 90 & 1.0 & & 1.0 & \\
\hline \multirow[t]{2}{*}{ Non-fatal CVD } & $\geq 30$ & 4,920 & 578 & $1.32(1.13-1.53)$ & $<0.001$ & $1.16(0.99-1.36)$ & NS \\
\hline & $<25$ & 2,676 & 269 & 1.0 & & 1.0 & \\
\hline
\end{tabular}

${ }^{\text {a }}$ Per $5 \mathrm{~kg} / \mathrm{m}^{2}$ increase in BMI as continuous variable, or comparison of two BMI intervals

${ }^{\mathrm{b}}$ Model 1: adjusted for age, sex, type of hypoglycaemic treatment, diabetes duration, smoking and significant interactions

${ }^{\mathrm{c}}$ Model 2: adjusted as in model 1, and also for $\mathrm{HbA}_{1 \mathrm{c}}$, systolic blood pressure, antihypertensive drugs, lipid-lowering drugs and microalbuminuria $>20 \mu \mathrm{g} / \mathrm{min}$

baseline, the adjusted hazard ratio (model 1) was higher for fatal CHD than for non-fatal CHD, $1.29(1.17-1.42)$ and 1.10 (1.03-1.17), respectively. Similarly, the relative risk was higher for fatal than for non-fatal CVD. Obesity compared with normal weight increased the risk of fatal CHD (79\%) more than the risk of non-fatal CHD (38\%), and increased the risk of fatal CVD (62\%) more than the risk of non-fatal CVD (32\%), after adjustment according to model 1.

Subgroup analyses The change in BMI during 6 years, from baseline to follow-up in 2003, was analysed in a subgroup of 4,916 patients with baseline BMI $25-40 \mathrm{~kg} / \mathrm{m}^{2}$ (Table 4). Median BMI change (10th-90th percentiles) in all these patients during the period was $0.0(-2.3$ to 2.4$) \mathrm{kg} / \mathrm{m}^{2}$. Cox regression analysis disclosed that the relative risk of fatal or non-fatal CHD was $1.13(1.04-1.23)$ per 1 unit increase in BMI during the period after adjustment according to model 2. Subgroup analysis was also performed to compare patients who gained most weight during the study (BMI increase $>2.5 \mathrm{~kg} / \mathrm{m}^{2}$; median gain $3.8 \mathrm{~kg} / \mathrm{m}^{2}$ ) with those who gained a little (BMI increase 0 to $2.5 \mathrm{~kg} / \mathrm{m}^{2}$; median gain $1.0 \mathrm{~kg} / \mathrm{m}^{2}$ ), with those who lost a little (BMI decrease 0 to $-2.5 \mathrm{~kg} / \mathrm{m}^{2}$; median loss $1.0 \mathrm{~kg} / \mathrm{m}^{2}$ ), and with those who lost most (BMI decrease $>2.5 \mathrm{~kg} / \mathrm{m}^{2}$; median loss $4.0 \mathrm{~kg} / \mathrm{m}^{2}$ ). When patients who gained most weight (BMI increase $>2.5 \mathrm{~kg} / \mathrm{m}^{2}$ ) were compared with each of the other three subgroups, the relative risk of CHD was between 1.8 and 2.3 and the relative risk of CVD was between 1.5 and 1.7 (model 2).

\section{Discussion}

Overweight and obesity are associated with increased risks of cardiovascular morbidity and mortality in the general population [8-12, 24-27], but only a few previous studies of type 2 diabetic patients have addressed the topic, and with somewhat conflicting results [13-16, 28-31]. Our large observational study clearly shows an increased risk of fatal/non-fatal CHD (15\%), stroke (11\%), CVD (13\%) and total mortality $(27 \%)$ with a 5 unit increase in BMI at baseline after adjustment for age, sex, diabetes duration, type of hypoglycaemic treatment and smoking (model 1), and the risks were attenuated, but remained significant (except for stroke), when also adjusted for additional cardiovascular risk factors (e.g. $\mathrm{HbA}_{1 \mathrm{c}}$, microalbuminuria, systolic blood pressure and use of lipid-lowering and antihypertensive treatment [model 2]). Furthermore, this study was able to demonstrate that not only obesity, but also overweight, increased the risk of fatal/non-fatal CHD and CVD in type 2 diabetic patients, according to both models 1 and 2. Obesity also significantly increased the risk of total mortality as well as the risk of a fatal CVD event. 
Table 4 Adjusted hazard ratios for change in BMI during the study period and first-incident fatal or non-fatal CHD, stroke and CVD and total mortality using Cox regression analysis in 4,916 overweight or obese (BMI $25-40 \mathrm{~kg} / \mathrm{m}^{2}$ ) type 2 diabetic patients followed-up for 6 years

\begin{tabular}{|c|c|c|c|c|c|c|}
\hline $\begin{array}{l}\text { BMI change } \mathrm{e}^{\mathrm{a}} \text { as } \\
\text { predictor }\end{array}$ & $\begin{array}{l}\text { BMI change }{ }^{\mathrm{a}} \text { (median, } \\
\text { 10th-90th percentile) }\end{array}$ & Outcome & Patients $(n)$ & Events $(n)$ & $\begin{array}{l}\text { Hazard ratio }{ }^{b} \\
(95 \% \mathrm{CI})\end{array}$ & $p$ value \\
\hline \multirow[t]{4}{*}{ Per 1 unit increase } & \multirow[t]{4}{*}{$0.0(-2.3$ to +2.4$)$} & Fatal/non-fatal CHD & 4,916 & 498 & $1.13(1.04-1.23)$ & 0.0047 \\
\hline & & Fatal/non-fatal stroke & 4,916 & 266 & $0.89(0.79-1.0)$ & NS \\
\hline & & Fatal/non-fatal CVD & 4,916 & 708 & $1.05(0.97-1.13)$ & NS \\
\hline & & Total mortality & 4,916 & 225 & $0.95(0.83-1.09)$ & NS \\
\hline Interval 1 & $+3.8(+2.6$ to +5.4$)$ & Fatal/non-fatal CHD & 430 & 62 & $1.80(1.22-2.65)$ & 0.0029 \\
\hline \multirow[t]{3}{*}{ Interval 2} & \multirow[t]{3}{*}{$+1.0(+0.1$ to +2.0$)$} & & 2,070 & 219 & 1.0 & \\
\hline & & Fatal/non-fatal CVD & 430 & 73 & $1.54(1.09-2.19)$ & 0.015 \\
\hline & & & 2,070 & 300 & 1.0 & \\
\hline Interval 1 & $+3.8(+2.6$ to +5.4$)$ & Fatal/non-fatal CHD & 430 & 62 & $2.35(1.45-3.81)$ & $<0.001$ \\
\hline \multirow[t]{3}{*}{ Interval 3} & \multirow[t]{3}{*}{$-1.0(-2.0$ to -0.2$)$} & & 1,977 & 174 & 1.0 & \\
\hline & & Fatal/non-fatal CVD & 430 & 73 & $1.74(1.14-2.67)$ & 0.011 \\
\hline & & & 1,977 & 260 & 1.0 & \\
\hline Interval 1 & $+3.8(+2.6$ to +5.4$)$ & Fatal/non-fatal CHD & 430 & 62 & $2.24(1.13-4.41)$ & 0.020 \\
\hline \multirow[t]{3}{*}{ Interval 4} & \multirow[t]{3}{*}{$-4.0(-6.1$ to -2.7$)$} & & 439 & 43 & 1.0 & \\
\hline & & Fatal/non-fatal CVD & 430 & 73 & $1.70(0.98-2.95)$ & NS \\
\hline & & & 439 & 75 & 1.0 & \\
\hline
\end{tabular}

Interval 1: BMI increase $>+2.5 \mathrm{~kg} / \mathrm{m}^{2}$; interval $2: 0$ to $+2.5 \mathrm{~kg} / \mathrm{m}^{2}$; interval $3:-2.5$ to $0 \mathrm{~kg} / \mathrm{m}^{2}$; interval $4:$ BMI decrease $>2.5 \mathrm{~kg} / \mathrm{m}^{2}$ ${ }^{\mathrm{a}} \mathrm{BMI}$ change equals final BMI minus baseline BMI

${ }^{\mathrm{b}}$ Model 2: adjusted for age, sex, type of hypoglycaemic treatment, diabetes duration, smoking, $\mathrm{HbA}_{1 \mathrm{c}}$, antihypertensive drugs, systolic blood pressure, lipid-lowering drugs, microalbuminuria $>20 \mu \mathrm{g} / \mathrm{min}$ and significant interactions

The results of our study, with obesity increasing the risk of total mortality by $71 \%$ (model 1 ), are supported by an observational study from Italy that followed 3,398 type 2 diabetic patients for 10 years, showing that obesity increased the risk of overall mortality by $74 \%$ in younger patients ( $<65$ years old) (adjustment as in model 1), whereas excess weight predicted better survival in older patients [16]. An increased risk for total mortality with obesity was seen in the large UK General Practice Research Database (GPRD) study on type 2 diabetic patients ( $N=44,230$, age 35-89 years, followed from 1992 to 1998), showing $13 \%$ and $43 \%$ increases in risk for BMI $30-34 \mathrm{~kg} / \mathrm{m}^{2}$ and $35-54 \mathrm{~kg} / \mathrm{m}^{2}$ compared with $20-24 \mathrm{~kg} / \mathrm{m}^{2}$, respectively (adjustment as in model 1) [28]. An older, smaller WHO study found no association between BMI and total mortality [13].

Concerning CHD, the Nurses' Health Study on type 2 diabetic women $(N=5,897$, age $40-74$ years, followed for 20 years) found that, compared with women with BMI $<23 \mathrm{~kg} / \mathrm{m}^{2}$, those with BMI $25-26.9 \mathrm{~kg} / \mathrm{m}^{2}$ had an $85 \%$ increased risk of non-fatal myocardial infarction and fatal CHD, those with BMI $27-29.9 \mathrm{~kg} / \mathrm{m}^{2}$ had a $95 \%$ increased risk and those with BMI over $30 \mathrm{~kg} / \mathrm{m}^{2}$ had a threefold increased risk (adjustment as in model 1) [14]. In the present study, overweight and obesity increased this risk by $27 \%$ and $49 \%$, respectively, compared with BMI $<25 \mathrm{~kg} / \mathrm{m}^{2}$ (model 1). The higher risk estimates in the Nurses' Health Study are probably explained by the lower reference BMI.

Our study showed that obesity increased the risk of fatal and non-fatal stroke by $33 \%$ above that of normal weight patients (model 1), although this was not significant when adjusted according to model 2 . The UK GPRD study ( $N=$ 41,799, age 35-89 years, followed from 1992 to 1999) found a significantly increased risk of stroke $(36 \%)$ only with BMI $>35 \mathrm{~kg} / \mathrm{m}^{2}$ compared with BMI $20-24 \mathrm{~kg} / \mathrm{m}^{2}$ (adjustment as in model 1 and for hypertension) [29], whereas in a UKPDS report, obesity was not independently associated with an increased risk of fatal or non-fatal stroke [30].

When BMI at baseline was used as a continuous variable, we found that the risk of CHD increased by $15 \%$ per 5 unit BMI increase according to model 1 , and by $9 \%$ according to model 2 (when adjustment included $\mathrm{HbA}_{1 \mathrm{c}}$, systolic blood pressure and lipid-lowering treatment as a marker of hyperlipidaemia), while UKPDS 23 found no significant association between $\mathrm{BMI}$ and fatal/non-fatal myocardial infarction when adjustment included $\mathrm{HbA}_{1 \mathrm{c}}$, systolic blood pressure and blood lipids [31]. The relatively large numbers of 13,087 participants and 1,326 events is a major strength of this study, compared with 2,693 patients and 192 events in the UKPDS, and this may be a main reason for the difference between these studies. BMI was also slightly higher in our study: $28.6 / 29.6 \mathrm{~kg} / \mathrm{m}^{2}$ (men/women) as compared with $27.1 / 29.4 \mathrm{~kg} / \mathrm{m}^{2}$ in the UKPDS. Furthermore, BMI was used as continuous variable in the present study, but as upper versus lower third in the UKPDS. Adjustment was made for age and diabetes duration in our study, but only for the lower age in newly diagnosed patients in the UKPDS. Our results were supported by the results of a recent meta-analysis by Bogers et al. [9] comprising more than 300,000 participants. 
BMI was shown to be an independent risk factor for CHD in that study, as the authors found the risk of CHD increased by $29 \%$ per 5 unit increase in BMI when adjusting for age, sex, physical activity and smoking, and by $16 \%$ when additionally adjusting for blood pressure and cholesterol.

In a large study of 243,000 overweight individuals [15], it was shown that the presence of hypertension considerably increased the risk of fatal CVD, and the risk was increased even more in the presence of diabetes and hypertension in combination, but not in the presence of hypercholesterolaemia alone. The authors concluded that hypertension in overweight individuals was strongly associated with the increased CVD risk. This points to the importance of adjusting for hypertension, which may possibly be even more important than adjusting for hyperlipidaemia. In the present study we have adjusted for both systolic BP and use of antihypertensive drugs, the two variables constituting the definition of hypertension. In the UKPDS, adjustments were made for systolic BP but not for the use of antihypertensive drugs.

WHO has addressed the issue of how to adjust for confounding factors with regard to BMI, suggesting that in order not to underestimate the risk associated with BMI, factors closely related to BMI such as hypertension, hyperlipidaemia, hyperglycaemia and microalbuminuria should not be considered confounding and adjustments should not be made [32]. Hence, according to WHO, our study model 1 is more correct and model 2 may underestimate the true risk. Taking this into consideration, we find that both models 1 and 2 add valuable information.

The use of both adjustment models also allowed Bogers et al. to conclude that the adverse effect of BMI on blood pressure and cholesterol could account for $45 \%$ of the increased risk of $\mathrm{CHD}$, with $55 \%$ caused by pathways currently unknown [9]. In the present study, we found that an adverse effect of $\mathrm{BMI}$ on $\mathrm{HbA}_{1 \mathrm{c}}$, blood pressure, hyperlipidaemia and microalbuminuria accounted for $40 \%$ $([1.15-1.09] /[1.15-1] \times 100)$ and $46 \%$ of the increased risks for CHD and CVD, respectively. Other variables (e.g. disturbed fibrinolysis, endothelial dysfunction and low-grade inflammation) are also most likely to be involved in the causal pathways between overweight and obesity and increased risk of CHD [33].

In our substudy of 4,916 overweight or obese type 2 diabetic patients with known weight change during the study, there was a $13 \%$ increase in the risk of fatal and nonfatal CHD per 1 unit increase in BMI. It also showed that patients who gained most weight during the study (median BMI change $+3.8 \mathrm{~kg} / \mathrm{m}^{2}$ ) had a 1.8 - to 2.3 -fold increase in risk of CHD compared with those who gained less weight or who lost weight. Weight change with regard to diabetes is a complex topic, as weight loss could reflect poorly controlled diabetes (few in this study), and weight gain could be attributable to pharmacological treatment to improve metabolic control [34]. The latter was accounted for by adjusting for the type of hypoglycaemic treatment. We also excluded patients with extreme obesity, and those with BMI $<25 \mathrm{~kg} / \mathrm{m}^{2}$ in order to minimise the number of patients with lower weight at baseline caused by concurrent illness. A previous study from the US on overweight and obese type 2 diabetes patients $(N=4,970$, followed 1959 1972) showed a $28 \%$ reduction in CVD mortality with intentional weight loss, with a U-shaped curve giving maximum risk reduction at a weight loss of $10-15 \%$ of initial weight [35]. Results from the Nurses' Health Study showed that weight increase before the diagnosis of diabetes was associated with an increased risk of CHD in women, whereas weight change after the diagnosis of diabetes was not [14]. A weight increase of 11-20 kg yielded a $50 \%$ increase in the risk of $\mathrm{CHD}$, whereas in our study an estimated BMI increase of 5 units would yield an $80 \%$ increase in the risk of CHD.

There are known limitations of observational studies such as this one. Data from participating centres may vary slightly in accuracy, although increased use of computer software with direct reporting of data has minimised this problem; the study cohort is also well characterised and only a few patients with missing data were excluded. Unfortunately, antibody measurements are not yet reported in the NDR. However, the epidemiological definition of type 2 diabetes used in this study should exclude most type 1 diabetic patients, as only $1 \%$ had an age at onset $<30$ years, and $3 \%$ had an age at onset $<40$ years; thus, only very few of the type 2 diabetic patients may have been misclassified as having latent autoimmune diabetes of the adult.

Blood lipid values and the presence or absence of atrial fibrillation were not recorded in the NDR in 1997, and this was a major limitation of this study. Although the use of lipid-lowering medication as a marker of hyperlipidaemia is a relatively weak substitute for blood lipids levels, we made this adjustment. However, previous comparable studies adjusting for the presence or absence of hyperlipidaemia or cholesterol levels have reached similar results [9, 12, 24]. The meta-analysis by Bogers et al. [9] found a hazard ratio of 1.29 for CHD when adjusting as in model 1, and 1.16 when additionally adjusting for blood pressure and cholesterol (45\% decrease), compared with 1.15 with model 1 and 1.09 with blood pressure and lipid-lowering drugs added in this study (40\% decrease). These results add support for the use of lipid-lowering drugs as a marker of hyperlipidaemia in the present study.

The large numbers of type 2 diabetic patients and events represent a major advantage of this study. Data were sampled from a national register representing patients on routine treatment in hospitals and primary-care centres nationwide, with no exclusions due to the presence or absence of risk factors or co-morbidities, as are often present in randomised 
controlled trials with limitations owing to strict inclusion or exclusion criteria. Additionally, study endpoints were retrieved by register linkage, a validated alternative to revised hospital discharge notes and death certificates [22, 23], based on clinicians' diagnoses, and registered in hospital discharge records and on death certificates.

To conclude, this large observational study based on Swedish clinical practice demonstrates a considerably increased risk for CHD, stroke and total mortality in overweight and obese type 2 diabetic patients, independent of well-known risk factors. The results provide additional evidence that overweight and obesity should be counteracted in type 2 diabetes, although randomised trials are needed to fully examine the cardiovascular effects of weight changes and weight-lowering non-pharmacological, pharmacological and surgical treatments.

Acknowledgements We would like to thank the regional NDR coordinators, all participating nurses, physicians and other staff who have contributed to the NDR. Most of all, we would like to thank the patients who support the NDR, both individually and collectively through their patient organisation, the Swedish Diabetes Federation. The Swedish Association of Local Authorities and Regions, and the Swedish Association for Diabetology fund the NDR. This study was also supported by an unrestricted research grant from Lilly Deutschland $\mathrm{GmbH}$, Germany.

Duality of interest statement The authors declare that there is no duality of interest associated with this manuscript.

\section{References}

1. Lipscombe LL, Hux JE (2007) Trends in diabetes prevalence, incidence, and mortality in Ontario, Canada 1995-2005: a population-based study. Lancet 369:750-756

2. Mokdad AH, Ford ES, Bowman BA et al (2003) Prevalence of obesity, diabetes, and obesity-related health risk factors, 2001. JAMA 289:76-79

3. Wild S, Roglic G, Green A, Sicree R, King H (2004) Global prevalence of diabetes: estimates for the year 2000 and projections for 2030. Diabetes Care 27:1047-1053

4. Gaede P, Vedel P, Larsen N, Jensen GV, Parving HH, Pedersen O (2003) Multifactorial intervention and cardiovascular disease in patients with type 2 diabetes. N Engl J Med 348:383-393

5. Haffner SM, Lehto S, Ronnemaa T, Pyorala K, Laakso M (1998) Mortality from coronary heart disease in subjects with type 2 diabetes and in nondiabetic subjects with and without prior myocardial infarction. N Engl J Med 339:229-234

6. Hu G, Jousilahti P, Qiao Q, Katoh S, Tuomilehto J (2005) Sex differences in cardiovascular and total mortality among diabetic and non-diabetic individuals with or without history of myocardial infarction. Diabetologia 48:856-861

7. Juutilainen A, Lehto S, Ronnemaa T, Pyorala K, Laakso M (2005) Type 2 diabetes as a "coronary heart disease equivalent": an 18year prospective population-based study in Finnish subjects. Diabetes Care 28:2901-2907

8. Adams KF, Schatzkin A, Harris TB et al (2006) Overweight, obesity, and mortality in a large prospective cohort of persons 50 to 71 years old. N Engl J Med 355:763-778
9. Bogers RP, Bemelmans WJ, Hoogenveen RT et al (2007) Association of overweight with increased risk of coronary heart disease partly independent of blood pressure and cholesterol levels: a meta-analysis of 21 cohort studies including more than 300000 persons. Arch Intern Med 167:1720-1728

10. Calle EE, Thun MJ, Petrelli JM, Rodriguez C, Heath CW Jr (1999) Body-mass index and mortality in a prospective cohort of U.S. adults. N Engl J Med 341:1097-1105

11. Jee SH, Sull JW, Park J et al (2006) Body-mass index and mortality in Korean men and women. N Engl J Med 355:779-787

12. Jonsson S, Hedblad B, Engstrom G, Nilsson P, Berglund G, Janzon L (2002) Influence of obesity on cardiovascular risk. Twenty-three-year follow-up of 22,025 men from an urban Swedish population. Int J Obes Relat Metab Disord 26:1046-1053

13. Chaturvedi N, Fuller JH (1995) Mortality risk by body weight and weight change in people with NIDDM. The WHO Multinational Study of Vascular Disease in Diabetes. Diabetes Care 18: 766-774

14. Cho E, Manson JE, Stampfer MJ et al (2002) A prospective study of obesity and risk of coronary heart disease among diabetic women. Diabetes Care 25:1142-1148

15. Thomas F, Bean K, Pannier B, Oppert JM, Guize L, Benetos A (2005) Cardiovascular mortality in overweight subjects: the key role of associated risk factors. Hypertension 46:654-659

16. Zoppini G, Verlato G, Leuzinger C et al (2003) Body mass index and the risk of mortality in type II diabetic patients from Verona. Int J Obes Relat Metab Disord 27:281-285

17. Ridderstrale M, Gudbjornsdottir S, Eliasson B, Nilsson PM, Cederholm J (2006) Obesity and cardiovascular risk factors in type 2 diabetes: results from the Swedish National Diabetes Register. J Intern Med 259:314-322

18. Saydah SH, Fradkin J, Cowie CC (2004) Poor control of risk factors for vascular disease among adults with previously diagnosed diabetes. JAMA 291:335-342

19. Eliasson B, Cederholm J, Nilsson P, Gudbjornsdottir S (2005) The gap between guidelines and reality: Type 2 diabetes in a National Diabetes Register 1996-2003. Diabet Med 22:1420-1426

20. Gudbjornsdottir S, Cederholm J, Nilsson PM, Eliasson B (2003) The National Diabetes Register in Sweden: an implementation of the St. Vincent Declaration for Quality Improvement in Diabetes Care. Diabetes Care 26:1270-1276

21. Hoelzel W, Weykamp C, Jeppsson JO et al (2004) IFCC reference system for measurement of hemoglobin A1c in human blood and the national standardization schemes in the United States, Japan, and Sweden: a method-comparison study. Clin Chem 50:166-174

22. Merlo J, Lindblad U, Pessah-Rasmussen H et al (2000) Comparison of different procedures to identify probable cases of myocardial infarction and stroke in two Swedish prospective cohort studies using local and national routine registers. Eur J Epidemiol 16:235-243

23. Tunstall-Pedoe H, Kuulasmaa K, Amouyel P, Arveiler D, Rajakangas AM, Pajak A (1994) Myocardial infarction and coronary deaths in the World Health Organization MONICA Project. Registration procedures, event rates, and case-fatality rates in 38 populations from 21 countries in four continents. Circulation 90:583-612

24. Hu G, Tuomilehto J, Silventoinen K, Sarti C, Mannisto S, Jousilahti P (2007) Body mass index, waist circumference, and waist-hip ratio on the risk of total and type-specific stroke. Arch Intern Med 167:1420-1427

25. Jood K, Jern C, Wilhelmsen L, Rosengren A (2004) Body mass index in mid-life is associated with a first stroke in men: a prospective population study over 28 years. Stroke 35:2764-2769

26. Kurth T, Gaziano JM, Berger K et al (2002) Body mass index and the risk of stroke in men. Arch Intern Med 162:2557-2562 
27. Kurth T, Gaziano JM, Rexrode KM et al (2005) Prospective study of body mass index and risk of stroke in apparently healthy women. Circulation 111:1992-1998

28. Mulnier HE, Seaman HE, Raleigh VS, Soedamah-Muthu SS, Colhoun HM, Lawrenson RA (2006) Mortality in people with type 2 diabetes in the UK. Diabet Med 23:516-521

29. Mulnier HE, Seaman HE, Raleigh VS et al (2006) Risk of stroke in people with type 2 diabetes in the UK: a study using the General Practice Research Database. Diabetologia 49:2859-2865

30. Davis TM, Millns H, Stratton IM, Holman RR, Turner RC (1999) Risk factors for stroke in type 2 diabetes mellitus: United Kingdom Prospective Diabetes Study (UKPDS) 29. Arch Intern Med 159:1097-1103

31. Turner RC, Millns H, Neil HA et al (1998) Risk factors for coronary artery disease in non-insulin dependent diabetes mellitus:
United Kingdom Prospective Diabetes Study (UKPDS: 23). BMJ 316:823-828

32. Report of a WHO Consultation (2000) Obesity: preventing and managing the global epidemic. World Health Organ Tech Rep Ser 894:1-253

33. Rahman S, Rahman T, Ismail AA, Rashid AR (2007) Diabetesassociated macrovasculopathy: pathophysiology and pathogenesis. Diabetes Obes Metab 9:767-780

34. Hermansen K, Mortensen LS (2007) Bodyweight changes associated with antihyperglycaemic agents in type 2 diabetes mellitus. Drug Saf 30:1127-1142

35. Williamson DF, Thompson TJ, Thun M, Flanders D, Pamuk E, Byers $T$ (2000) Intentional weight loss and mortality among overweight individuals with diabetes. Diabetes Care 23:14991504 